\title{
The metaphor police: A case study of the role of metaphor in explanation
}

\author{
Paul H. Thibodeau ${ }^{1} \cdot$ Latoya $^{\text {Crow }}{ }^{1} \cdot$ Stephen J. Flusberg $^{2}$
}

Published online: 7 December 2016

(C) Psychonomic Society, Inc. 2016

\begin{abstract}
While many scholars have pointed to the role of metaphor in explanation, relatively little experimental research has examined whether and how metaphors are used and understood in everyday explanatory discourse. Across 3 experiments, we investigated the nature and function of metaphor in explanation by drawing on a real-world example where the terms guardian and warrior were used to metaphorically explain the role of police officers. We found, first, that the associations participants brought to mind for these concepts differed depending on whether they had previously answered questions about law enforcement (e.g., associations for warrior emphasized aggression and violence rather than strength and bravery when participants had previously answered questions about policing). Second, people were almost evenly split in their judgment of which metaphor was more appropriate to explain the role of law enforcement; this preference was highly predictive of beliefs related to policing and the criminal justice system. Third, and most important, using these metaphors to explain the job of policing causally
\end{abstract}

Electronic supplementary material The online version of this article (doi:10.3758/s13423-016-1192-5) contains supplementary material, which is available to authorized users.

Paul H. Thibodeau

paul.thibodeau@oberlin.edu

Latoya Crow

latoya.crow@oberlin.edu

Stephen J. Flusberg

stephen.flusberg@purchase.edu

1 Department of Psychology, Oberlin College, 120 W. Lorain St., Oberlin, OH 44074, USA

2 Department of Psychology, Purchase College, SUNY, 735 Anderson Hill Rd., Purchase, NY 10577, USA influenced attitudes toward law enforcement in a metaphorcongruent manner (i.e., exposure to the guardian metaphor led to more positive attitudes), a finding that could not be accounted for by basic lexical priming. These studies complement existing work that has identified metaphor as a mechanism for representing abstract concepts, but also highlight the communicative and explanatory, rather than representational, functions of metaphor by showing that metaphors can encapsulate and convey an array of structured attitudes and beliefs.

Keywords Metaphor $\cdot$ Explanation · Analogy $\cdot$ Persuasion · Reasoning · Concepts

Explanations without metaphor would be difficult if not impossible, for in order to describe the unknown, we must resort to concepts that we know and understand, and that is the essence of a metaphor - an unusual juxtaposition of the familiar and the unfamiliar.

Earl R. MacCormac

When you are trying to explain something complex or abstract to someone else, it often helps to make a vivid comparison to a simpler and more familiar domain. In other words, it often helps to use a metaphor or analogy. An apt metaphor can quickly establish common ground between communicative partners, add emotional weight to the discussion, and enable the listener to use their prior knowledge of a source domain to organize their understanding and reasoning about the target of explanation (Clark, 1996; Thibodeau \& Boroditsky, 2011, 2013). Take, for example, some explanations of the nature of explanation itself: in order to highlight the ubiquity of explanation in everyday experience, Wilson and Keil (2000) 
remarked, "Explanation is a river that flows through human life" (p. 87). And in a chapter that appeared in the same edited volume, Alison Gopnik (2000) famously explained the phenomenology (and evolutionary origins) of explanation by analogy to an orgasm.

Yet despite the recent explosion of research in psychology and the cognitive sciences into the nature of explanation, almost none of this work has directly examined the role of metaphor in this process. Similarly, though there has been a great deal of theoretical, linguistic, and experimental research into the nature and functions of metaphor in language and thought, scant attention has been paid to how metaphors are used and understood in the context of everyday explanatory discourse. Rather, most of the focus has been on the cognitive mechanisms underlying metaphor processing (e.g., Gentner, Bowdle, Wolff, \& Boronat, 2001; Glucksberg \& Keysar, 1990; Kao, Bergen, \& Goodman, 2014), the representational role metaphors play in abstract thinking (e.g., Boroditsky, 2000; Gibbs, 1994; Lakoff \& Johnson, 1980; Lakoff \& Núñez, 2000; Thibodeau \& Boroditsky, 2011, 2013), and the persuasive power of metaphors in communication (e.g., Ottati, Rhoads, \& Graesser, 1999; Sopory \& Dillard, 2002).

Taken together, however, this work points to the potential power of metaphor as an explanatory device, since metaphors (and analogies) allow us to represent, understand, and reason about novel domains by subsuming them under familiar schematic knowledge structures (Gentner et al., 2001; Gentner \& Gentner, 1982; Glucksberg \& Keysar, 1990; Lakoff \& Johnson, 1980; Thibodeau \& Boroditsky, 2011). This process dovetails with subsumption or unificationist accounts of the structure and function of explanations developed by philosophers of science, which suggest that successful explanations situate the target of explanation under broad, unifying patterns or theories, guiding the learner to generalize and make predictions based on these more abstract schemata (Lombrozo, 2011; Woodward, 2014). Experimental research on the role of self-explanation in category learning provides empirical support for this approach to thinking about the nature of explanation: People prompted to explain (as opposed to describe) their decisions during learning are more likely to make inferences about the general rules governing category membership (Williams \& Lombrozo, 2010). We suggest metaphors function as useful and efficient explanatory devices precisely because they situate the target of explanation in relation to a broad, structured body of knowledge already stored in longterm memory (i.e., knowledge of the metaphor vehicle), which is then available to drive generalizations, predictions, and inference about the target domain.

One real-world example of metaphor in explanation comes from a recent report prepared by President Obama's (Ramsey \& Robinson, 2015) task force on 21 st century policing: "Law enforcement culture should embrace a guardian - rather than a warrior - mindset to build trust and legitimacy both within agencies and with the public" (emphasis added; Ramsey \& Robinson, 2015, p. 1). The task force chose to communicate their central message by contrasting two metaphors for policing: the term warrior highlights the similarity between police officers and soldiers, who fight not just for their cause but also for their lives - an unfortunate reality of policing that is often pointed out in recruitment and training materials, as in "You could die today, tomorrow, or next Friday" (Garcia, 2014, para. 3). The term guardian, on the other hand, emphasizes that protecting and serving the community is the core mission of police. We used this real-world example as test bed for investigating foundational questions about the nature and function of metaphor in explanation:

1. How is knowledge about a metaphorical source domain (guardian or warrior) activated in the context of a metaphorical explanation (about policing)?

2. Does preference for a given metaphorical source domain (police officers are more like guardians than warriors or vice versa) predict particular attitudes toward the target domain?

3. Are explanatory metaphors effective? That is, does using a specific metaphorical source domain during explanation affect listener conceptions of the target domain in a metaphor-congruent manner? If so, what cognitive processes are involved?

\section{Overview of studies}

We present the results of three studies that explored the relationship between metaphors for and conceptions of policing. The goal of Study 1 was to investigate what the terms guardian and warrior mean in order to identify how they might influence peoples' conceptions of policing when used as explanatory metaphors, as well examine whether preference for one of the metaphors is predictive of attitudes toward law enforcement.

In Study 2 we asked whether the metaphors used in the service of explanation are persuasive. A growing body of evidence suggests that metaphorical framing can impact how people think and reason about complex social issues (e.g., Dweck, 2006; Hauser \& Schwarz, 2014; Landau, Sullivan, \& Greenberg, 2009; Sopory \& Dillard, 2002; Thibodeau \& Boroditsky, 2011, 2013). For example, describing a crime problem as a beast that is ravaging a city leads people to suggest more aggressive crime-fighting solutions compared to when the same problem is described as a virus (Thibodeau \& Boroditsky, 2011, 2013). We hypothesized that a similar effect would be observed when metaphors were used in the service of framing an explanation; in other words, we expected that reading a statement explaining how police 
officers are guardians of the community would lead people to a more positive view of role of law enforcement than reading a statement explaining how police officers are warriors of the community.

In Study 3, we tested whether the power of an explanatory metaphor is simply the result of lexical priming (cf. McGlone, 2011). Do people report more positive views of police when exposed to a guardian metaphor because activation from the word guardian spreads to positively valenced lexical associates like protection? Do people report more negative views of police when exposed to a warrior metaphor because activation in this case spreads to more negatively valenced lexical associates like war? Or, does the explanatory power of the words come from their explicit use as metaphors to describe policing? In this study, participants were asked to report their attitudes toward law enforcement either after listing a synonym to a target word (guardian or warrior) or after reading a metaphorical description of police (as guardians or warriors). We expected that presenting the word guardian or warrior in isolation, disconnected from a discussion of policing, would not influence attitudes about police (Thibodeau \& Boroditsky, 2011).

This pattern of results would suggest that metaphors are useful in explanation at least in part because of the schematic knowledge structures that they bring to bear on the topic of discussion (Sopory \& Dillard, 2002; Thibodeau \& Boroditsky, 2011), and not simply because of the emotional valence they convey. That is, we argue that metaphors help to organize complex information about the target domain (policing) in terms of a more general and less complex source domain (guardian or warrior), which is subsequently available to guide reasoning. Quantifying the conceptual structure of these domains and testing for such an influence represents an important challenge for researchers interested in how metaphors shape thought (e.g., Keysar \& Bly, 1995). We present one approach to this issue based on finer grained analyses of our key dependent measure after discussing the primary findings of the three studies. Data for all three studies are available on the Open Science Framework (osf.io/6twj8).

\section{Study 1: Guardians and warriors}

Participants in Study 1 completed four tasks: they (1) listed words and concepts they associated with guardian and warrior, (2) answered targeted questions gauging their attitudes toward policing, (3) identified which metaphorguardian or warrior - they considered more appropriate to describe the current state of policing in the United States, and (4) explained why they chose the metaphor they did. We manipulated the order of the association-listing task so that some participants would generate associates to "guardian" and "warrior" in a neutral context and others would generate associates to the terms in a policing context.

One salient dimension that appears to differentiate guardian and warrior metaphors for policing is the emotional valence that the metaphor vehicles convey. Explaining that police officers are guardians of the community seems to cast a much more positive light on policing. However, in a neutral context, both terms have been found to express a similarly positive valence $\left(M_{\text {guardian }}=6.50, S D=1.99 ; M_{\text {warrior }}=\right.$ $5.50, S D=2.21), t(38)=1.50, p=.14$, according to a recent norming study of a large set of English words (Warriner, Kuperman, \& Brysbaert, 2013). Thus, the negative valence that the warrior metaphor conveys in a policing context seems to emerge from an interplay between the topic of discussion (policing) and source domain (warrior).

To test this possibility, we quantified the positive and negative valence of the associations that participants generated in response to guardian and warrior in a neutral and policing context using the Linguistic Inquiry and Word Count software (LIWC; Pennebaker, Chung, Ireland, Gonzales, \& Booth, 2010). We expected the word guardian to elicit positive associations in both contexts, but warrior to elicit more negative responses in a policing context because a warrior concept is less consistent with an idealized model of policinghighlighting the combative, rather than protective, role of police (Stoughton, 2015).

At a theoretical level, this finding would support interactionist models of metaphor processing (e.g., Black, 1979), which suggest that metaphoric vehicles like warrior are more than lexical primes and often convey different meanings in different contexts (Thibodeau \& Durgin, 2011). When a professional baseball player or college professor is described as a warrior, the phrase may highlight perseverance and strength in the face of adversity. However, when a police officer is described as a warrior, the comparison seems to emphasize qualities that are less desirable-drawing out a more negative (aggressive, violent, rash) sense of the word.

Consistent with the valence that guardian and warrior convey in a policing context, we expected to find a relationship between the metaphor that participants felt best captures the current state of policing and their attitudes toward law enforcement. That is, we expected participants who identified police officers as guardians to express a more positive attitude toward law enforcement and the criminal justice system compared to participants who identified police officers as warriors.

\section{Method}

\section{Participants}

Participants in all three studies were recruited and paid through Amazon's Mechanical Turk. We required that 
participants live in the U.S. and have an approval rating greater than $90 \%$ on prior Turk tasks. At the end of the survey, participants were given a completion code; participants who failed to submit a correct completion code were excluded from analysis. Sample sizes were set to be consistent with (or larger) than recent work on linguistic framing (e.g., Dweck, 2006; Hauser \& Schwarz, 2014; Landau et al., 2009; Thibodeau \& Boroditsky, 2011, 2013). Demographic information for all three samples is shown in Table 1.

\section{Materials and design}

There were two between-subjects conditions in the first study. One third of participants $(n=89)$ were asked to list associations with the two target concepts (warrior and guardian) in isolation (a neutral context). These participants were not asked about their attitudes toward law enforcement. The other two thirds of participants $(n=192)$ were presented with the same free association task, but only after responding to targeted questions about their views on policing (a policing context).

Free association All participants were asked two freeresponse questions: "What are some qualities of a warrior?" and "What are some qualities of a guardian?" The order of these two questions was counterbalanced across participants. We used the LIWC (Pennebaker et al., 2010) to count the number of words generated by participants and to quantify the responses along two target dimensions: the degree to which the responses expressed "positive" and "negative" valence. Words that indicate positive emotion is being expressed include care, kind, helpful, and strong (and cognates). Words that indicate negative emotion is being expressed include $a g$ gressive, fight, violent, and war (and cognates). The LIWC has been shown to reveal patterns of results that converge with other methodologies (e.g., human coding of qualitative data; Pennebaker \& Chung, 2005) and is a tool that can facilitate more consistent and objective measurement and analysis of qualitative data.

One potential limitation of the LIWC is that it reflects both the writer and what is being written about. Terms like "care"

Table 1 Demographic information by sample for Studies 1-3

\begin{tabular}{llll}
\hline & Study 1 & Study 2 & Study 3 \\
\hline Sampled & 300 & 350 & 800 \\
Analyzed & 281 & 319 & 787 \\
Female & $55 \%$ & $62 \%$ & $59 \%$ \\
Mean age & $36.5(13.2)$ & $38.5(13.4)$ & $35.2(11.4)$ \\
Race: White & $78 \%$ & $87 \%$ & $78 \%$ \\
Democrats; Republicans & $42 \% ; 23 \%$ & $36 \% ; 23 \%$ & $39 \%, 23 \%$ \\
Conservativeness & $42.5(28.1)$ & $44.0(27.9)$ & $43.9(26.5)$ \\
\hline
\end{tabular}

are counted as indicating a positive valence, regardless of whether they are used in a phrase like "I care" or in a phrase like "guardian's care." However, a careful inspection of participants' responses to the prompts revealed that their descriptions focused on the prompts (i.e., we found no cases of a participant writing "I care," "I think," or "I feel"). Thus, we interpret the data generated by the LIWC as reflecting conceptions of the target concepts - guardian and warrior - rather than the participants themselves.

Attitudes toward policing An eight-item survey was developed to gauge participants' attitudes toward policing. Three of the questions were asked on a 7-point scale: "Police officers have a _ job" (from very easy to very difficult), "Police officers are _at maintaining law and order" (from very ineffective to very effective), and "How would you describe the criminal justice system in the U.S.?" (from very far from the ideal to very near to the ideal). The other five questions were two-alternative multiple choice, asking about whether participants thought police treated citizens equally (yes/no), whether they thought the police were more fair or unfair, more honest or deceitful, more selfish or selfless, and whether participants felt safe or unsafe around police officers.

Because the eight questions were highly related - both conceptually and empirically $(\alpha=.79, .75$, and .76 in Studies 1, 2, and 3, respectively) - they were combined into a single measure of attitudes toward policing for the primary analyses (items are analyzed separately in the Breaking Down Attitudes Toward Policing section). We used principal components analysis to combine the responses to the eight questions, using Varimax rotation (Mardia, Kent, \& Bibby, 1980). Principal components analysis is a statistical procedure for revealing the internal structure of a dataset with interrelated measures in a way that best explains the common variance of the data (Dunteman, 1989). An inspection of the Scree and the Kaiser criterion (i.e., only one eigenvalue was greater than 1) confirmed that responses to the eight survey items were best explained by a single source of variance (more than $45 \%$ of the variance in the responses was captured by the first factor; see Table 2 for factor loadings). ${ }^{1}$ The units of this dimension are centered and normalized; we have shifted them up by two units so that all of the reported means are positive.

Metaphor preference Participants who were asked about their attitudes toward policing were also asked (a) "Which metaphor (guardian or warrior) do you think better describes policing in the U.S. today?" and (b) "Which metaphor do you think better describes the ideal model of policing in the U.S.?" After making these judgments, participants were asked to

\footnotetext{
${ }^{1}$ It is worth noting that other reliable and valid psychological scales have also combined binary and Likert-scale responses into singular measures (e.g., the original 32 item Disgust Scale; see Haidt, McCauley, \& Rozin, 1994).
} 
Table 2 Factor loadings computed by principal components analysis

\begin{tabular}{lllllllll}
\hline & Job difficulty & Efficacy & Equal & Fair & Honest & Selfless & Safe & Justice system \\
\hline Loading & .29 & .39 & .24 & .41 & .41 & .37 & .35 & .32 \\
\hline
\end{tabular}

explain the reasoning behind their answer to question (a). Two naïve coders categorized these responses as more "positive" or "negative" (Cohen's $\mathrm{K}=.86$; disagreements were resolved in discussion).

We also analyzed participants' explanations with the LIWC. On the LIWC-based analysis, we were interested in whether participants extended the language of the metaphor they chose. We created two new dictionaries to do this: one for guardian and one for warrior. The guardian dictionary contained the 10 words (and cognates) that were most frequently generated by participants in response to "guardian" in a neutral context (e.g., care, protect, love)—excluding words that were also among the 10 most frequently generated in response to "warrior" (e.g., strong). The warrior dictionary contained the 10 words (and cognates) that were most frequently, and uniquely, provided in response to "warrior" in a neutral context (e.g., brave, fearless, tough; see supplement for LIWC dictionaries). The words "guardian" and "warrior" were not included in either dictionary.

Background questions At the end of the study, all participants were asked about their gender, age, political ideology (on a continuous scale from 0 , very liberal, to 100 , very conservative), political affiliation (categorically as Democrat, Republican, or Independent), and racial identity (see Table 1 and supplement).

\section{Results}

Free association: What do people associate with guardians and warriors within and outside of a policing context?

Our first goal was to gauge what the words guardian and warrior mean — both in a neutral and policing context - by using the LIWC to quantify the valence of participants' associations with the terms (see Table 3). A two-way mixed ANOVA with predictors for term (guardian or warrior; within subjects) and context (neutral or policing; between subjects) revealed no differences in the number of words that participants used to respond to the prompts, $F \mathrm{~s}<.6, p \mathrm{~s}>.4$, suggesting that the quantity of associations that people had with the two concepts was similar and independent of the context in which they were probed.

However, a three-way ANOVA with predictors for term (guardian or warrior), context (neutral or policing), and valence (positive and negative) revealed a significant three-way interaction, $F(1,837)=10.93, p<.001$, suggesting that the emotional content of these responses differed - by concept and by context. As shown in the left panel of Fig. 1, the terms elicited similar levels of positive emotion in a neutral context, $t(88)=.95, p=.346$, but guardian elicited marginally more positive emotion than warrior in policing context, $t(191)=$ $1.79, p=.075, d=.13$. As shown in the right panel of Fig. 1, warrior elicited more negative emotion in both a neutral, $t(88)=5.49, p<.001, d=.82$, and policing context, $t(191)=12.44, p<.001, d=1.27$. This suggests that the term warrior conveys a more negative valence overall. However, the context manipulation had a much stronger impact on participants' responses to warrior than guardian. Participants responded somewhat less positively, $t(279)=4.81, p<.001$, $d=.60$, and more negatively, $t(279)=2.40, p=.017, d=.34$, to guardian in a policing, compared to a neutral, context; they responded much less positively, $t(279)=6.18, p<.001, d=$ .76 , and much more negatively, $t(279)=5.09, p<.001, d=$ .70 , to warrior in a policing, compared to a neutral, context. In other words, although warrior seems to convey more negative valence than guardian overall, using the term to describe police officers seems to draw out an especially negative connotation of the word.

These patterns can also be seen in the most common words used to describe a guardian and warrior (see Table 4). The word strong appears frequently in responses to both words in both contexts. However, considering the full scope of frequent words suggests that guardian calls to mind an image of

Table 3 Means (and SDs) for target dimensions computed by the Linguistic Inquiry and Word Count software by context (neutral or policing) and term (guardian or warrior)

\begin{tabular}{lllll}
\hline Dimension & \multicolumn{2}{l}{ Neutral $(n=89)$} & & \multicolumn{2}{l}{ Policing $(n=192)$} \\
\cline { 2 - 3 } & Guardian & Warrior & Guardian & Warrior \\
\hline Word count & $7.79(10.35)$ & $7.74(7.74)$ & $8.56(8.15)$ & $8.47(8.08)$ \\
Positive & $38.07(30.02)$ & $41.10(33.22)$ & $21.43(25.44)$ & $18.00(27.04)$ \\
Negative & $0.73(2.75)$ & $9.91(16.62)$ & $2.30(5.86)$ & $23.63(23.07)$ \\
\hline
\end{tabular}



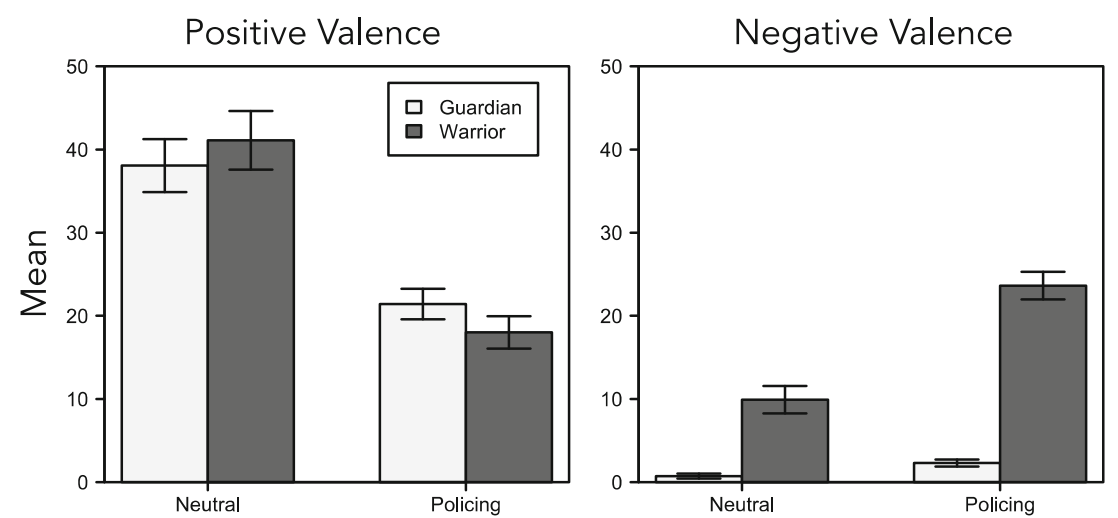

Fig. 1 Positive (left) and negative (right) valence associated with the guardian and warrior terms by context (neutral or policing), as quantified by the Linguistic Inquiry and Word Count software. Error bars denote standard errors of the means

compassionate protection, whereas warrior makes violence more salient, especially in a policing context.

\section{Attitudes toward policing}

A second way in which we quantified what the metaphors mean was by asking people to choose whether they thought police officers were more like guardians or warriors of the community. Overall, $82 \%$ of participants reported thinking that police officers should, ideally, strive to be guardians of the community, $\chi^{2}(1, N=192)=77.52, p<.001$. However, only $60 \%$ of participants reported thinking that the guardian metaphor more accurately describes the current state of policing in the U.S., $\chi^{2}(1, N=192)=7.52, p=.006$. This latter judgment was highly predictive of participants' attitudes toward policing, $t(190)=6.84, p<.001, d=1.01$. As illustrated in the leftmost bars of Fig. 2, participants who identified police officers as guardians $(M=2.58, S D=1.51)$ reported a more positive view of policing than participants who identified police officers as warriors $(M=0.70, S D=2.29)$.

\section{How do people explain which metaphor they think is more accurate?}

Finally, at the end of the first study, participants were asked to explain why they chose the guardian or warrior metaphor to describe how they think about policing. Explanations for why people chose the guardian metaphor tended to emphasize the protective or defensive role that police officers play in society, whereas explanations for why people chose the warrior metaphor tended to focus on the police force's capacity for violence.

Using the LIWC to quantify the tone of responses revealed a statistically significant interaction between the metaphor chosen (guardian or warrior) and valence (positive or negative), $F(1,190)=9.42, p=.002$. Participants' explanations were similarly positive for why they chose guardian $(M=$ $2.40, S D=5.19)$ or warrior $(M=1.98, S D=4.75), t(190)=$ $.56, p=.575$, but explanations for choosing warrior $(M=$ $7.43, S D=11.51)$ were significantly more negative than explanations for choosing guardian $(M=3.10, S D=6.20)$, $t(190)=3.37, p<.001, d=.50$.

A similar pattern emerged when two naïve coders categorized participants' explanations as "positive" or "negative." Of the $60 \%$ of participants who chose the guardian metaphor, $96 \%$ described positive qualities of police officers or their impact on the community. Of the $40 \%$ of participants who chose the warrior metaphor, only $13 \%$ described positive features of policing, $\chi^{2}(1)=130.96, p<.001$.

Interestingly, participants often used language that extended the guardian and warrior metaphors in their explanations, further suggesting that the metaphors provided a structure for

Table 4 The five most frequent words used to describe guardian and warrior in a neutral and policing context. The number of times each word appeared is shown in parentheses

\begin{tabular}{lllll}
\hline Frequency Rank & \multicolumn{2}{l}{ Neutral context $(n=89)$} & & \multicolumn{2}{l}{ Policing context $(n=192)$} \\
\cline { 2 - 3 } & Guardian & Warrior & Guardian & Warrior \\
\hline 1 & Caring (29) & Strong (46) & Protect (28) & Aggrong (32) \\
2 & Protect (26) & Brave (29) & Strong (15) & Fight (28) \\
3 & Loving (14) & Fearless (18) & Safe (12) & Brave (25) \\
4 & Kind (12) & Tough (12) & Watchful (9) & Violent (18) \\
\hline
\end{tabular}




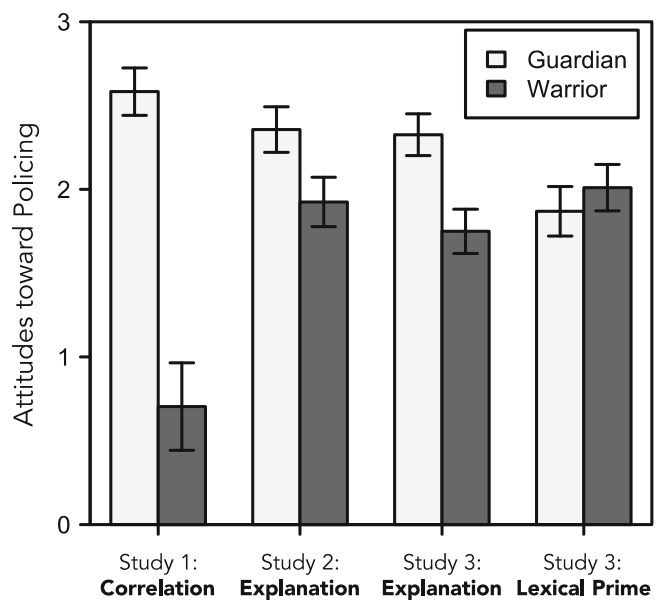

Fig. 2 Attitudes toward policing as a function of metaphor preference in Study 1 (the correlational study), and either as a function of which metaphor was used to explain the role of polices officers in Studies 2 and 3 or the lexical prime that participants saw in Study 3. Higher scores indicate more positive attitudes. Error bars represent standard errors of the means

thinking about police. For example, two explanations for choosing the warrior metaphor described police officers as "armed and looking for people to capture" and "prone to battle"; one stated that "there is a thin line between chaos and civility." To quantify this tendency to extend the metaphor, we created a guardian dictionary and a warrior dictionary in the LIWC: the dictionaries were built from the freeassociation data-from the 89 participants who listed associations to guardian and warrior in a neutral context; then they were used to analyze the explanations generated by the other 192 participants in Study 1 (i.e., the ones who answered questions about policing). We found that people who thought guardian was a better metaphor for policing used more guardian language $(M=9.75, S D=13.98)$ to explain their choice than people who thought warrior was a better metaphor for policing $(M=2.43, S D=11.63), t(190)=3.79, p<$ $.001, d=.56$. On the other hand, people who thought warrior was a better metaphor for policing use more warrior language $(M=3.31, S D=7.65)$ to explain their choice than people who thought guardian was a better metaphor for policing $(M=$ $0.60, S D=3.10), t(190)=3.41, p<.001, d=.50$.

\section{Discussion}

The results of Study 1 revealed that the associations people brought to mind for the terms guardian and warrior differed depending on whether or not they had previously answered questions about law enforcement: associations for both concepts were overwhelmingly positive when probed in a neutral context; however, associations with "warrior" were especially negative when participants had previously answered questions about policing, emphasizing aggression and violence rather than strength and bravery.
This finding is consistent with the observation that people selectively import knowledge of a source domain in the service of metaphor comprehension. The word jail, for example, brings to mind different associations when you are describing where your inebriated friend spent the night than when you are (metaphorically) describing your job (as in, "my job is a jail"). This has been taken as evidence that (some) metaphors may be processed as category-inclusion statements, where the source domain functions as a prototypical exemplar of a broader schematic concept that the target domain is then placed into (e.g., a jail is prototypical example of a dreadful confining space you cannot leave, much like some people's jobs; see Glucksberg \& Keysar, 1990). In other words, the specific associations and relational structure that are transferred from a given source domain (e.g., warrior) depend on the topic of discussion (Black, 1979). The meanings of metaphoric vehicles, like the meanings of words and phrases in general, are not static but can change dramatically as a function of the context in which they are used (Thibodeau \& Durgin, 2011).

Another key finding of Study 1 that builds on this insight was that participants were almost evenly split in their judgment of which metaphor - guardian or warrior - was more appropriate to explain the role of law enforcement, and this preference was highly predictive of participants' attitudes toward policing. People who think of police officers as guardians of the community reported a more positive view of policing. Interestingly, when people explained why they chose a specific metaphor, they often extended their preferred metaphor in the service of their explanation. These results support the view that metaphors play a key role in how people represent and reason about complex domains, and highlight the utility of metaphor as an explanatory device that helps people make sense of and communicate about complicated subjects.

One important issue that Study 1 did not address is whether or not explanatory metaphors actually affect how listeners understand and think about the target of explanation. In promoting the role of police as the guardians (and not warriors) of the community, one important goal of the Obama task force has been to persuade the public that how we think about law enforcement needs to change. Therefore, in Study 2 we tested whether explaining the role of police officers using these metaphors would influence participant attitudes toward policing.

\section{Study 2: Testing explanatory metaphors}

\section{Method}

\section{Participants}

Data from 350 participants were collected for Study 2, also from Mechanical Turk, using the same inclusion criteria as Study 1, which left data from 319 participants for analysis (see Table 1). 


\section{Materials and design}

There were two between-subjects conditions in Study 2, which varied in how they (metaphorically) explained the role of police officers. One read, "Police officers are the guardians of modern communities - strong men and women who serve a vital role in society, often placing themselves in harm's way in order to protect their fellow citizens," while the other explained, "Police officers are the warriors of modern communities - strong men and women who serve a vital role in society, often placing themselves in harm's way in order to fight for their fellow citizens" (italics added). Of note, in addition to a difference in the metaphor used to describe police officers, the guardian condition highlighted that police officers strive to "protect" citizens, while the warrior condition emphasized that police officers "fight for" their fellow citizens. These were the most common verbs associated with two terms and were included in Study 2 to stress different ways of conceptualizing law enforcement. To ensure that differences between conditions were the result of the explanatory metaphors, and not these verbs, however, we used more consistent phrasing in Study 3.

After participants read the description of police officers, they responded to the same eight questions about their attitudes toward policing and the same demographic and background questions as in Study 1.

\section{Results}

As illustrated in Fig. 2, participants who read that police officers are guardians of the community $(M=2.36, S D=1.71)$ reported a more positive attitude toward policing than participants who read that police officers are warriors of the community $(M=2.08, S D=1.86), t(317)=2.16, p=.032, d=.24$.

\section{Discussion}

The results of Study 2 revealed that explanatory metaphors causally impacted people's attitudes towards law enforcement. Participants who were exposed to the guardian metaphor expressed more positive views of the police than participants exposed to the warrior metaphor. A follow-up study-described in detail in the online Supplementary Material-also found that exposure to the guardian metaphor made people more likely think that the demographic characteristics of a police force should match the demographic characteristics of the communities they serve, and less likely support the view that police should have access to military-grade weaponry. These findings suggest that metaphors may be especially useful when the speaker's goal is to influence the listener's attitudes toward the target of explanation.

There are two potential limitations of Study 2 that are addressed in Study 3. First, as noted above, the two conditions in
Study 2 differed not only in how they metaphorically explained the role of police officers in the community but also with respect to the verbs used to describe police officers (as seeking to "protect" vs. "fight for" the community). Thus, it is possible that the difference in conditions resulted from a difference in these verbs rather than the explanatory metaphors.

Second, it may be the case that the words guardian and warrior do not need to be used as metaphors to influence people's conception of policing. Just as these words seem to take on a different meaning in a policing context, the meaning of police may differ depending on whether people have recently been exposed to the word guardian or warrior, regardless of whether the term is used to metaphorically explain the role of police officers in the community. For example, it may simply be that exposure to the term warrior primes more negative thoughts and feelings, which results in more negative attitudes toward law enforcement across the board. Though we think it is likely that metaphor framing effects result in part from the low-level spread of activation from the metaphor vehicle (see Flusberg, Thibodeau, Sternberg, \& Glick, 2010; Thibodeau, 2016), we expected explanatory metaphors to be most influential when used explicitly to frame the topic of discussion. We tested this possibility in Study 3 .

\section{Study 3: Lexical priming}

\section{Method}

\section{Participants}

Data from 800 participants were collected for Study 3, also from Mechanical Turk, using the same inclusion criteria as Studies 1 and 2, which left data from 787 participants for analysis.

\section{Materials and design}

In Study 3, half of the participants were presented with a metaphorical description of police before being asked about their attitudes toward policing. The descriptions were similar to those of Study 2, but, importantly, only differed in the metaphoric frame. The explanation comparing police officers to guardians read, "Police officers are the guardians of modern communities. They are strong men and women who serve a vital role in society." The explanation comparing police officers to warriors read, "Police officers are the warriors of modern communities. They are strong men and women who serve a vital role in society" (emphasis added).

The other half of participants were asked to list a synonym to either guardian or warrior on one screen, and then were presented with a nonmetaphorical description of police on the following screen ("Police officers are strong men and women 
who serve a vital role in society") before being asked about their attitudes toward law enforcement. The most common synonyms given for guardian were protector (38\%), parent (23\%), and caretaker (12\%). The most common synonyms given for warrior were fighter (55\%), soldier (29\%), and hero $(4 \%)$.

Finally, participants were asked the same background and demographic questions as in Studies 1 and 2.

\section{Results}

The goal of Study 3 was to test whether the effects found in Study 2 were the result of the explanatory metaphor or simply the result of lexical priming. A between-subjects ANOVA with predictors for term (guardian or warrior) and task (explanatory metaphor or synonym) on participants' attitudes toward policing revealed a statistically significant interaction between the two factors, $F(1,783)=6.922, p=.009$. Neither main effect was statistically significant, $p \mathrm{~s}>.1$. Planned pairwise comparisons revealed that participants reported more positive attitudes toward policing after reading that police officers were guardians $(M=2.33, S D=1.71)$ than warriors $(M=1.75, S D=1.87), t(387)=3.16, p=.002, d=$ .32 ; in contrast, there was no difference between the two conditions in which participants listed a synonym - for guardian $(M=1.87, S D=2.06)$ or warrior $(M=2.01, S D=1.97)$, $t(396)=.70, p=.486$.

In addition, participants reported more favorable views of policing when guardian was used as an explanatory metaphor than a lexical prime, $t(382)=2.36, p=.019, d=.24$. There was no difference in attitudes toward policing as a function of how warrior was used, $t(401)=1.36, p=.175, d=.14$. These effects are illustrated in the two rightmost pairs of bars in Fig. 2.

\section{Discussion}

The results of Study 3 replicated and extended the results of Study 2. Participants who read that police officers are guardians of the community reported more positive attitudes toward policing than participants who read that police officers are warriors of the community. On the other hand, participants who listed a synonym for guardian did not report more positive attitudes toward policing compared to participants who listed a synonym for warrior. This suggests that explanatory metaphors are most influential when used explicitly to frame the topic of discussion, and that lexical priming cannot fully account for these effects.

So far, we have focused on the emotional valence of the terms guardian and warrior because one way in which explanatory metaphors seem to influence how people think is by casting the topic of discussion in a more positive or negative light. We do not think this is the only way in which explanatory metaphors influence thought, however-although it may be easiest to quantify. For one thing, the results of Study 1 demonstrate that the term warrior calls to mind more negatively valenced associations than guardian, even in a neutral context. If the only mechanism at work in these studies were the activation of negative affect, we would have expected the lexical priming manipulation in Study 3 to result in a similar shift in attitudes toward law enforcement as the metaphorical framing manipulation. As illustrated in Fig. 2, this was certainly not the case.

In addition to conveying emotional resonance, therefore, we suggest explanatory metaphors work in part by helping to situate the target of explanation under a broader (and more familiar) schematic domain (e.g., guardians), which the listener can then use in the service of reasoning. In other words, metaphors facilitate the subsumptive or unifying function of explanation (Lombrozo, 2011; Williams \& Lombrozo, 2010; Woodward, 2014) by providing a candidate schema or pattern (e.g., police officers have the properties of and behave like guardians) for thinking about the target of explanation (e.g., Flusberg et al., 2010; Gentner et al., 2001; Glucksberg \& Keysar, 1990; Sopory \& Dillard, 2002).

Notably, this account makes specific predictions about how participants in Studies 2 and 3 should be affected by the explanatory metaphors. Namely, the metaphors should have a larger effect on survey items that directly tap into the actual entailments of the guardian and warrior metaphors and a smaller effect on items that do not. Next, we use the results of Study 1 to identify specific ways in which an explanation that metaphorically describes polices officers as guardians or warriors should affect peoples' conception of law enforcement. Then we test whether the explanatory metaphors used in Studies 2 and 3 actually resulted in patterns of responding that reflected these more nuanced predictions.

\section{Breaking down attitudes toward policing}

\section{Method}

In our analysis of Studies 1-3, we treated responses to eight target questions about participants' attitudes toward policing as a unified measure. Here we analyze responses to different types of questions separately. Recall that three of the questions were rated on 7-point scales: asking participants to judge how difficult it is to be a police officer (difficulty), how effectively the police have enforced the law (efficacy), and how fairly the criminal justice system treats citizens (justice system). Participants were also asked five binary questions: whether or not they think the police treat people equally, fairly, honestly, selflessly, and whether they feel safe around police officers. For the present analysis, we combined responses to these 
binary questions ( $\alpha=.79, .73$, and .75 in Studies 1,2 , and 3, respectively) into a fourth scalar measure (police officers).

First, we examined how well participants' endorsement of the guardian or warrior metaphors for policing in Study 1 predicted the four outcome measures. Then we tested how strongly the explanatory metaphors influenced these measures in Studies 2 and 3. For brevity, we have pooled the data from Studies 2 and 3 (excluding the condition in which participants listed a synonym for guardian or warrior in Study 3); there was no overall difference in participants' attitudes toward policing by Study ( 2 or 3 ) or interaction between metaphor condition (guardian vs. warrior) and Study, $p \mathrm{~s}>.4$.

\section{Results}

As shown in Table 5, the results of the correlational study (Study 1) suggest that that the two metaphors for policing describe some aspects of policing more aptly than others, $F(3,570)=14.29, p<.001$. Specifically, participants who endorsed the guardian metaphor over the warrior metaphor reported a much more favorable view of police officers, $t(190)$ $=6.86, p<.001, d=1.01$, and the criminal justice system, $t(190)=6.42, p<.001, d=.94$. Although the guardian metaphor was also associated with thinking that it was somewhat more difficult to be a police officer, $t(190)=1.97, p=.051, d=$ .29 , and thinking police officers were more effective at maintaining law and order, $t(190)=4.46, p<.001, d=.66$, participants' choice of metaphor was less predictive of these assessments.

Table 5 shows that the influence of the explanatory metaphors (in Studies 2 and 3) mirrored this pattern - with a stronger influence on participants' responses to some questions and a weaker influence on responses to others, $F(3,2118)=3.56$, $p=.014$. Specifically, the framing manipulation had a more pronounced influence on participants' views of police officers, $t(706)=3.74, p<.001, d=.28$, and the criminal justice system, $t(706)=3.73, p<.001, d=.28$, and a lesser influence on judgments of how difficult it was to be a police officer, $t(706)=1.41, p=.159, d=.11$, and how effectively the police have maintained law and order, $t(706)=2.27, p=.023, d=.17$ (see Fig. 3 for a comparison of effect sizes).

Table 5 Mean judgments (and $S D$ s) of four subcomponents of participants' attitudes toward policing as a function of which metaphor participants chose to describe police officers (Study 1) or which metaphor

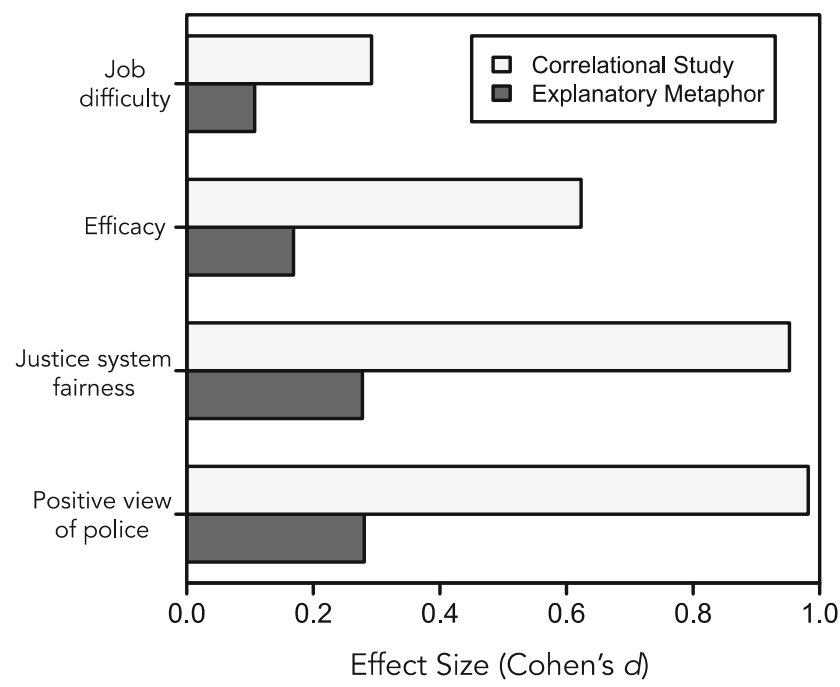

Fig. 3 Comparison of effect sizes (Cohen's $d$ ) from Study 1 on four outcome measures (as a function of which metaphor participants thought more accurately described the police) to effect sizes elicited from the explanatory metaphor in Studies 2 and 3 (pooled data)

The relationship between these patterns of results-from a situation in which participants explicitly compared the metaphors and chose one deliberately to express how they thought about policing (Study 1) and a situation in which the metaphors were used to explain the role of police officers in the community (Studies 2 and 3)-suggests that these explanatory metaphors capture and convey more than an emotional tone. Instead, these metaphor vehicles seem to instantiate different schematic knowledge structures for thinking about policing and the criminal justice system (Boroditsky, 2000; Gibbs, 1994; Lakoff \& Johnson, 1980; Thibodeau \& Boroditsky, 2011).

\section{General discussion}

Across three studies, we investigated the role metaphors play in the process of explanation using a real-world case study of police metaphors. Study 1 revealed that participants who considered police to be guardians expressed more positive attitudes toward law enforcement and felt the justice system was

was used to explain the role of police officers in the community (Studies 2 and 3)

\begin{tabular}{|c|c|c|c|c|}
\hline & \multicolumn{2}{|l|}{ Study 1: Correlational } & \multicolumn{2}{|c|}{ Studies 2 and 3: Explanatory } \\
\hline & Guardian $(n=115)$ & Warrior $(n=77)$ & Guardian $(n=348)$ & Warrior $(n=360)$ \\
\hline Difficulty & $6.36(1.00)$ & $6.05(1.12)$ & $6.64(0.83)$ & $6.33(1.00)$ \\
\hline Efficacy & $5.50(0.86)$ & $4.75(1.47)$ & $5.36(1.19)$ & $5.16(1.23)$ \\
\hline Justice system & $2.99(0.84)$ & $2.19(0.84)$ & $2.84(0.98)$ & $2.57(0.96)$ \\
\hline Police officer & $3.75(1.30)$ & $2.23(1.76)$ & $3.47(1.36)$ & $3.07(1.47)$ \\
\hline
\end{tabular}


more fair and effective than those who considered police to be warriors. What's more, in explaining why they chose the metaphor they did, participants often extended the metaphor itself in the service of their explanation. This suggests that they were using the metaphor to organize and structure their reasoning about the domain of law enforcement. Consistent with previous work on metaphor comprehension, Study 1 also revealed that associations with "warriors" and "guardians" differed depending on whether they were probed in a neutral or policing context. This highlights the fact that schematic knowledge of the source domain is dynamically brought to bear on the target domain (Black, 1979; Glucksberg \& Keysar, 1990; Lakoff \& Johnson, 1980). A given metaphor vehicle will not have the same effect on reasoning in all contexts (e.g., warrior metaphors are not always negatively valenced).

The results of Study 2 demonstrated that metaphors can be effective explanatory devices: using the guardian versus warrior metaphor to explain the job of policing causally influenced peoples' conceptions of policing, giving rise to more positive attitudes overall. This is consistent with previous work showing that metaphor framing can influence how people represent and reason about complex social issues (Sopory \& Dillard, 2002; Thibodeau \& Boroditsky, 2011, 2013). Study 3 revealed that this was not merely a result of lexical priming: The metaphor had to appear in the context of the explanation itself in order to exert a causal influence on participants' attitudes. Additional analyses examining specific aspects of participants' attitudes toward policing and the criminal justice system further support the view that these metaphors instantiate different conceptual entailments.

Taken together, these findings help illuminate why metaphors are useful tools in the process of explanation. Metaphors allow us to represent a complex, abstract, or novel domain in terms of a familiar and often simpler conceptual schema that we already understand. Thus, when we explain something using an appropriate metaphor, we can enrich listener understanding by encouraging them to use the knowledge they already have of the source domain to structure their thinking about the target of the explanation (Clark, 1996). This fits with a subsumption or unificationist account of the nature of explanation (Lombrozo, 2011; Williams \& Lombrozo, 2010; Woodward, 2014) and helps explain why metaphors and analogies play such an important role in both science education and scientific practice (Aubusson, Harrison, \& Ritchie, 2005; Brown 2003; Gentner \& Gentner, 1982; Gentner \& Jeziorski, 1993).

Finally, these studies highlight an often-underappreciated pragmatic feature of how explanations function in everyday communicative practice: When people explain things to someone else, they are not always just interested in increasing listener understanding as such; rather, they want the listener to think about the target of explanation in the same way they do. In other words, explanation often includes an element of persuasion. As our findings reveal, it is possible to think about the police using either a guardian or warrior metaphor, and the population we sampled was roughly split on this issue. And yet, as the authors of the Obama task force report were hoping, using one of these metaphors in particular during the course of explanation had an effect on how our participants came to conceptualize the nature and role of law enforcement. We suggest that this pragmatic dimension of explanation, and the role metaphor in this process (and in the process of explanation more generally) remains an important area for future research.

In sum, the present studies help to illuminate both how and why metaphors are useful tools the service of explanation. They can efficiently encapsulate and communicate an array of structured attitudes and beliefs, and can guide people to think about a target domain in new ways. Recent violent clashes between law enforcement and civilians have generated a national conversation about the role of police officers in our communities, and the present research suggests that we need to pay careful attention to the metaphors we use to support our explanations (much as the Obama Task Force has attempted to do already).

\section{References}

Aubusson, P. J., Harrison, A. G., \& Ritchie, S. M. (2005). Metaphor and analogy in science education (Vol. 30). New York, NY: Springer Science \& Business Media.

Black, M. (1979). More about metaphor. In A. Ortony (Ed.), Metaphor and thought (pp. 19-43). Cambridge, UK: Cambridge University Press.

Boroditsky, L. (2000). Metaphoric structuring: Understanding time through spatial metaphors. Cognition, 75, 1-28.

Brown, T. L. (2003). Making truth: Metaphor in science. Chicago: University of Illinois Press.

Clark, H. H. (1996). Using language. Cambridge, UK: Cambridge University Press.

Dunteman, G. H. (1989). Principal components analysis. Newbury Park, CA: SAGE Publications.

Dweck, C. (2006). Mindset: The new psychology of success. New York: Random House.

Flusberg, S. J., Thibodeau, P. H., Sternberg, D. A., \& Glick, J. J. (2010). A connectionist approach to embodied conceptual metaphor. Frontiers in Psychology, 1(197), 1-11.

Garcia, U. J. (2014, March 22). Experts say strongly worded police curriculum is risky with cadets. Santa Fe New Mexican. Retrieved from $\mathrm{http}: / / \mathrm{www}$. santafenewmexican.com/news/local news/experts-saystrongly-worded-police-curriculum-is-risky-with-cadets/article_6 fcb7d45-436c-5e48-aa06-2fc6fdcc35a1.html

Gentner, D., Bowdle, B., Wolff, P., \& Boronat, C. (2001). Metaphor is like analogy. In D. Gentner, K. J. Holyoak, \& B. N. Kokinov (Eds.), The analogical mind: Perspectives from cognitive science (pp. 199253). Cambridge, MA: MIT Press.

Gentner, D., \& Gentner, D. R. (1982). Flowing waters or teeming crowds: Mental models of electricity. In D. Gentner \& A. L. Stevens (Eds.), Mental models. Hillsdale, NJ: Erlbaum. 
Gentner, D., \& Jeziorski, M. (1993). The shift from metaphor to analogy in western science. In A. Ortony (Ed.), Metaphor and thought (2nd ed.). Cambridge, UK: Cambridge University Press.

Gibbs, R. W. (1994). The poetics of mind: Figurative thought, language, and understanding. Cambridge, UK: Cambridge University Press.

Glucksberg, S., \& Keysar, B. (1990). Understanding metaphorical comparisons: Beyond similarity. Psychological Review, 97(1), 3-18.

Gopnik, A. (2000). Explanation as orgasm and the drive for causal understanding: The evolution, function and phenomenology of the theory-formation system. In F. Keil \& R. Wilson (Eds.), Cognition and explanation (pp. 299-323). Cambridge, MA: MIT Press.

Haidt, J., McCauley, C., \& Rozin, P. (1994). Individual differences in sensitivity to disgust: A scale sampling seven domains of disgust elicitors. Personality and Individual Differences, 16(5), 701-713.

Hauser, D. J., \& Schwarz, N. (2014). The war on prevention bellicose cancer metaphors hurt (some) prevention intentions. Personality and Social Psychology Bulletin, 41, 66-77.

Kao, J. T., Bergen, L., \& Goodman, N. D. (2014). Formalizing the pragmatics of metaphor understanding. Proceedings of the 36th annual Meeting of the Cognitive Science Society. Retrieved from https:/mindmodeling.org/cogsci2014/papers/132/

Keysar, B., \& Bly, B. (1995). Intuitions of the transparency of idioms: Can one keep a secret by spilling the beans? Journal of Memory and Language, 34, 89-109.

Lakoff, G., \& Johnson, M. (1980). Metaphors we live by. Chicago, IL: University of Chicago Press.

Lakoff, G., \& Núñez, R. E. (2000). Where mathematics comes from: How the embodied mind brings mathematics into being. New York, NY: Basic books.

Landau, M. J., Sullivan, D., \& Greenberg, J. (2009). Evidence that selfrelevant motives and metaphoric framing interact to influence political and social attitudes. Psychological Science, 20, 1421-1427.

Lombrozo, T. (2011). The instrumental value of explanations. Philosophy Compass, 6(8), 539-551.

Mardia, K. V., Kent, J. T., \& Bibby, J. M. (1980). Multivariate analysis. New York, NY: Academic Press.

McGlone, M. S. (2011). Hyperbole, homunculi, and hindsight bias: An alternative evaluation of conceptual metaphor theory. Discourse Processes, 48(8), 563-574.

Ottati, V., Rhoads, S., \& Graesser, A. C. (1999). The effect of metaphor on processing style in a persuasion task: A motivational resonance model. Journal of Personality and Social Psychology, 77(4), 688697.

Pennebaker, J. W., \& Chung, C. K. (2005). Tracking the social dynamics of responses to terrorism: Language, behavior, and the Internet. In S. Wessely \& V. N. Krasnov (Eds.), Psychological responses to the new terrorism: A NATO-Russia dialogue. Amsterdam, The Netherlands: ISO Press.

Pennebaker, J. W., Chung, C. K., Ireland, M., Gonzales, A., \& Booth, R. J. (2010). The LIWC2007 application. Available at: http://www.liwc. net/LIWC2007LanguageManual.pdf

Ramsey, C., \& Robinson, L. (2015). Final report. The President's task force on 21st century policing. Retrieved Oct 28, $2016 \mathrm{https}$ ://cops. usdoj.gov/pdf/taskforce/taskforce_finalreport.pdf

Sopory, P., \& Dillard, J. P. (2002). The persuasive effects of metaphor: A meta-analysis. Human Communication Research, 28(3), 382-419.

Stoughton, S. (2015). Law enforcement's "warrior" problem. Harvard Law Review Forum, $128(6)$. Retrieved from http://harvardlawreview.org/2015/04/law-enforcements-warriorproblem/

Thibodeau, P. H. (2016). Extended metaphors are the home runs of persuasion: Don't fumble the phrase. Metaphor and Symbol, 31(2), 53 72.

Thibodeau, P. H., \& Boroditsky, L. (2011). Metaphors we think with: The role of metaphor in reasoning. PLoS ONE, 6(2), e16782.

Thibodeau, P. H., \& Boroditsky, L. (2013). Natural language metaphors covertly influence reasoning. PLoS ONE, 8(1), e52961.

Thibodeau, P. H., \& Durgin, F. H. (2011). Metaphor aptness and conventionality: A processing fluency account. Metaphor and Symbol, 26(3), 206-226.

Warriner, A. B., Kuperman, V., \& Brysbaert, M. (2013). Norms of valence, arousal, and dominance for 13,915 English lemmas. Behavior Research Methods, 45(4), 1191-1207.

Williams, J. J., \& Lombrozo, T. (2010). The role of explanation in discovery and generalization: Evidence from category learning. Cognitive Science, 34(5), 776-806.

Wilson, R. A., \& Keil, F. (2000). The shadows and shallows of explanation. In F. Keil \& R. Wilson (Eds.), Cognition and explanation (pp. 87-114). Cambridge, MA: MIT Press.

Woodward, J (2014, Winter). Scientific explanation. In E. N. Zalta (Ed.), The Stanford encyclopedia of philosophy. Retrieved from http://plato.stanford.edu/archives/win2014/entries/scientificexplanation/ 